\title{
Recorridos solidarios: trayectorias individuales $y$ montajes colectivos en la historia reciente
}

Rebeca Monroy Nasr

Departamento de Estudios Históricos

Instituto Nacional de Antropología e Historia, México

remona@mac.com

Patricia Pensado Leglise y Gerardo Necoechea Gracia (coords.), Recorridos solidarios: trayectorias individuales y montajes colectivos en la historia reciente, México, Instituto Mora, 2020, 241 pp.

\section{Los caminos recorridos con solidaridad}

Hoy más que nunca repensemos en el término "solidaridad”, cada vez más compleja ante la ominosa realidad que nos circunda, pensemos dónde ponernos, detenernos y pensarla frente a los feminicidios, a las desapariciones, las matanzas, los enfermos y la presencia infausta del Covid-19. Dónde ponernos cuando la sensación del primer momento es la de sentirse inundado de emociones tal vez la de acompañar o tal vez llorar, gritar, buscar para encontrarlos vivos/vivas, muertos/muertas, recuperar cuerpos, ver los rostros, detectar los elementos perdidos, indicios mínimos, pero estando presentes siempre presentes.

Ahora la vida a cambiado, nos ha trastornado el camino andado, y persiste la necesidad más que nunca de compañía y solidaridad, desde la ausencia, desde la distancia, pensar cómo serlo en medio de la pandemia, con tantos muertos y tantos contagios. Con el miedo a flor de piel. Tantos momentos duros de la existencia en estos momentos de la covida-19 del 2020, qué hacer ante las muertes, más aún de los golpes o las ausencias de las mujeres, pero también por todos aquellos que se van

\section{(c) (1) (9)}

4.0 Internacional

Secuencia. Reseñas, 2021

http://secuencia.mora.edu.mx
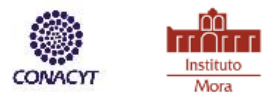
por este virus y desaparecen de la tierra, sin un funeral ni una compañía, una mínima solidaridad con sus parientes, sus seres queridos. Pensemos cómo podemos ser solidarios a la distancia, es un reto que no habíamos sentido con este impacto, desde hace un centenar de años. Por ello es preciso pensar y repensar después de leer este libro, con la introducción sobre todo la cual nos permite aprender y conocer las múltiples formas: colectivas, performáticas, intermitentes y/o construidas que se dan en el diario andar.

En este libro de Recorridos solidarios coordinado por dos grandes investigadores que admiro y respeto por su trabajo profundo y serio: Patricia Pensado Leglise y Gerardo Necoechea contiene diversas facetas muy importantes para comprender la solidaridad ciudadana. Es parte sustancial de un elemento que nos ha caracterizado en los últimos años, sobre todo si partimos de la idea de que nos hemos enfrentado a eventos poco usuales, que han alterado profundamente nuestra vida y que gracias a la solidaridad hemos podido enfrentar de diversas maneras, como lo han sido los terremotos, repetidos en una fecha que se empeña en sus horrores telúricos del 19 de septiembre (1985 y 2017) y ahora esta pandemia.

SOLIDARIDAD, si es la palabra que contiene diversos profundos significados y significantes, es lo que nos muestran los diez autores que componen esta obra, y que nos la dejan ver desde la macro hasta la microhistoria, con un profundo trabajo de investigación desde la perspectiva de una dialéctica de la historia en donde la solidaridad es recorrida en diversos momentos y con diferentes perspectivas histórico, sociales y culturales.

Gerardo Necoechea en la introducción realiza un profundo análisis que brinda muestras claras de un recorrido historiográfico del concepto de solidaridad con profundidades claras. Un análisis que aborda el concepto desde sus orígenes con los romanos, pasando por el cristianismo y el catolicismo, que se evidencia en la fe, la esperanza y la caridad, que toma matices entre la solidaridad y el consenso. Su análisis lo dirige después a la diferenciación del ámbito entre lo político y lo filosófico, que para el autor, va a tomar caminos diferenciados. La revisión desde Comte, Leroux, Reymond Williams, quien definirá los polos opuestos de la solidaridad burguesa de la cultura obrera. Para arribar al pensamiento posmoderno 
con Rorty, Durkheim, Leon Duguit, Chandra Talpade, Roediger, Dussel. El autor en su análisis recupera la noción de conflicto de Derrida que instituye en el concepto de solidaridad. Es un mosaico rico en lecturas, visiones filosófico-políticas en un análisis muy bien construido.

Es con esta herramienta, con la que podemos arrancar para comprender a profundidad este texto, rico en lecturas y texturas de personajes y eventos. Es un material imperdible para quien desee analizar la solidaridad ciudadana macro y micro en nuestro momento actual.

Gerardo Necoechea presenta lo que va a ser el constructo del libro en dos grandes apartados, por un lado, la solidaridad performativa la de la acción positiva y ética, que constituye los primeros ensayos. Y después, un segundo apartado se configura bajo el concepto de la solidaridad construida, es el caso específico de lazos ciudadanos que se realizan con personajes o personas que requerían de una ayuda, un lazo, un afecto, un pedazo de hilo de vida para poder continuar.

Esta solidaridad construida, concepto entramado del doctor Necoechea, deja en claro cómo es factible abordar el estudio en caso particulares, que denotan claridad de las acciones humanas con el deseo de ayudar al de junto, al de a lado, a los que están necesitando una ayuda inminente.

En ese primer apartado de la solidaridad performativa la investigadora Patricia Pensado nos muestra los lazos trazados por los trabajadores del SUTIN (Sindicato Único de Trabajadores de la Industria Nuclear) tan importantes en los años setenta, con sus trabajos cotidianos, pero ante todo cómo canalizaron su rebeldía y capacidad organizativa, los cuales nos mostraron algunos caminos a seguir desde la perspectiva de los movimientos sindicales y sociales y la presencia de la militancia con un profundo mecanismo de solidaridad introyectada a partir de la conciencia de clase. La cual se generó con la presencia inicial en el STERM y Rafael Galván, "figura emblemática del sindicalismo mexicano", como lo señala la autora. Un recorrido histórico sindical que merece una buena lectura para comprender los lazos ideológicos y políticos del movimiento del SUTIN con el SUTERM y la corriente democrática. Que tuvo una fuerte carga e influencia en la creación del STUNAM, del sindicato de la UAM y de la FAT (abogados independientes). Es la historia oral, el 
testimonio el que dará paso a concretar todos estos planeamientos de la solidaridad performativa... "es decir con acciones directas de apoyo".

Así como nos permite apreciar la misma investigadora Patricia Preciado junto con Erik Arellano Aguilar, Pablo Bonilla Juárez, Ricardo Chávez Cruz, becarios del Mora, los momentos más álgidos del 68, en donde el magisterio mostró su capacidad de presencia, integración y solidaridad en aquel momento de desconcierto $\mathrm{y}$ desasosiego no sólo estudiantil, sino urbano que afectó a familias, trabajadores y diversos sectores sociales que mostraron su capacidad organizativa, resiliente en eventos de ardua represión por parte del gobierno en turno. Ahí estuvieron presentes los maestros con una larga tradición de lucha en el recién terminado siglo XX, entre las voces se escuchan a profesores de larga tradición en Estudios Latinoamericanos, de la Facultad de Filosofía y Letras, de la Facultad de Ciencias de la UNAM y de la Escuela de Arquitectura e Ingeniería del Politécnico. Figuras como la "Chata" Campa o la voz de Ernesto Schettino, con Norma de los Ríos y otros profesores de esos años previos y del 68 mexicano se escuchan de manera clara en esa solidaridad performativa. Justo la de la acción.

Para Amelia Rivaud nos presenta la solidaridad intermitente, presente en los hijos de los combatientes enmontañados, como lo señala la autora. El caso de una chica que estuvo desde los cinco a los 15 años en escuelas alternativas, guarderías en tres países distintos, sus padres militantes, escapando de la autoridad. Con ello se busca analizar la solidaridad como un valor ético de la izquierda con el caso de $N R$, nació y fue cuidada por militantes solidarios, ella no tiene recuerdos antes de los cinco años, no debió ser fácil su vida, tampoco la de sus padres, incrustados en la guerrilla guatemalteca, por eso se trasladan a Guatemala a esa edad es cuidada por el colectivo la "Colmena". Después en 1977 muere su madre y su padre se ve obligado a regresar a México en 1978, sin saberse los motivos. Con "melón o con sandía" la vida de $N R$ transita entre el cobijo y el rechazo por los pleitos internos entre los militantes, cuando su padre decide escindir de la guerrilla salvadoreña, ya estando en Cuba. De nuevo la elección le significa quedarse desprotegida o perder a su padre, intermitencia en la solidaridad porque cuando eres de los míos funciona, cuando no se acaba, como ella lo narra. Intermitencia dolorosa que se vuelve con los años en 
solidaridad militante. Me recuerda esa intermitencia en la que vivimos en el día a día en la búsqueda de los 43 de Ayotzinapa y de muchas mujeres que permanecen en ausencia, dolencia y muerte. La intermitencia de la solidaridad que se genera y se diversifica en momentos diversos.

Gloria Luz Rascón Martínez nos narra la experiencia de la Escuelita de la Libertad Socialista en el año 2013, producto de la lucha del EZLN, con la idea de ver el "nosotros", con entrevistas a una mexicana, una brasileña y un alemán quienes dan paso a la comprensión de los logros y limitantes de la Escuelita que procuraba dar sustento a los niños en el ámbito ético de los procederes de justicia, libertad y democracia con las bases de la organización colectiva de la comunidad zapatista. Es el "nosotros", "el escuchar", "todo vive y tiene corazón”, "lo complementario", paradigmas claros que dan origen, vivencia y profunda convicción de la comunidad. Con Timo el alemán, Cheron la brasileña y Verónica la mexicana son los constructores de los testimonios y su experiencia en la Escuelita, eso sí desde el corazón y la entraña de la selva lacandona. Son, me parece, elementos sustanciales para comprender la nueva manera de enseñanza, aprendizaje y vida de esas comunidades zapatistas alternativas y vanguardistas. Creo que estos tres viajeros del tiempo lograron aprender mucho más para su vida después de Escuelita como lo analiza la autora.

Gerardo Necoechea penetra en las "Contiendas laborales y solidaridades encontradas en Santa Bárbara”, un pueblo minero de Chihuahua con sus respectivos problemas heredados de años atrás del abandono de sus trabajadores, de su salud y sus magros salarios. El rescate de los testimonios de determinados activistas mineros son pieza fundamental, por su experiencia, pero además porque su labor y entrega los llevó a ser despedidos. Y con estos testimonios se recupera el concepto de la solidaridad desde "la acción cuya repetición en el tiempo se convierte en práctica", de ese modo se acerca a las luchas mineras entre 1970 y 1981, con las huelgas de 1975 y 1981. Es con Everardo, Javier y Ricardo, con quien al autor destacará los lazos de comunidad y clase como base de la solidaridad erigida. Everardo enfrentando enfermedades terminales, responsabilidad de las empresas, sindicatos, lealtades de clase, la familia como nexo solidario, con conciencia de clase, estudioso nocturno, 
implacable en sus búsquedas. Dos huelgas por derechos mínimos la de 1975 y la de 1981, apoyos locales, de las tienditas, de los vecinos, pero sobre todo en la del 81 la presencia de otros sindicatos nacionales. Es aquí donde vemos la colectividad intensa con la fuerza solidaria de los "otros" que pasaban por las mismas condiciones de abuso e injusticia laborales y nacionales. Maravilloso texto que mezcla los testimonios de los tres mineros de manera singular, en un diálogo interno con otros actores, que al final vieron cómo una huelga se resquebrajaba ante una alianza de líderes sindicales con la empresa, así el movimiento mismo y las fisuras hondas también en la solidaridad se presenta de manera clara.

Por su parte J. Carlos Flores Flores nos presenta un ensayo que analiza "Construyendo la solidaridad. Análisis microhistórico de una mujer migrante", en donde pone en la mesa de manera clara la mutabilidad de la solidaridad, pues cómo él señala, no hay una sola forma de ésta, y depende del contexto en el que se desarrolle. Con su personaje, Cleo le permitió encontrar y cotejar la solidaridad de grupo familiar, desde la perspectiva de la microhistoria italiana, los estudios anarquistas y de género. Migrante del campo en los años cincuenta Cleo llegó con el sueño del milagro mexicano, vive y labora para una tía abusiva, que la lleva a buscar opciones de vida, aún más cuando su padre que es un hombre de tránsito entre el campo y la vida obrera muere. Encontrar algún techo para liberarse de la tía la lleva a sentirse "arrimada" a vivir otra serie de abusos que la condicionan a pensar en otra salida: "Le pedía a diosito un esposo... y diosito me lo concedió". Con una solidaridad restringida como la llama el autor, con apoyos intermitentes de sus propios hermanos o tíos, quienes buscaban encontrar su propio camino sólido en la economía familiar, sus hermanas como sirvientas, su hermano que era también asalariado. Encontró su sustento como obrera en diversas empresas también gracias al apoyo de vecinos. Pero fue con su pareja con quien fundó, no sin pocos esfuerzos, un concepto de ayuda mutua, de solidaridad para salir adelante desde la perspectiva de "trabajar los dos siempre". Es con su familia nuclear con quien logra salir adelante en un claro caso de solidaridades rotas, intermitentes y resilientes.

María Concepción Martínez Ocaña, trabaja la solidaridad también desde un estudio de caso con un personaje realmente atractivo por sus capacidades múltiples. 
Esta aproximación que realiza la autora nos deja ver a un joven con debilidad visual, de origen mixe, oaxaqueño, emprendedor y muy revelador que se llama Juventino. La presentación de este joven con deseos de estudiar y construirse un futuro diferente que no fuese desde la mirada lastimera y de autocompasión, nos permitirá comprender el ámbito en el que se desarrolló a pesar de depender de su familia de base en un primer momento, luego al migrar a la ciudad depender de su tía para sus cuidados médicos, y finalmente, el desarrollo de Juventino tendría grandes alcances. $\mathrm{Y}$ en ello, la autora condensa un enfoque desde la discapacidad y sus retos, los significados de solidaridad como práctica y acción directa, y la solidaridad armónica y conflictiva. Finalmente, el propio Juventino como en el caso de Cleo, se convierte en repartidor y generador de actos de solidaridad, aunado a su lucha por mejorar las condiciones de estudio, trabajo y vida de los discapacitados visuales, de trabajar la autoestima, de no mermar en el intento de una mejor vida, con su grupo de Punto 6, A.C., en donde el afirma que las mujeres son triplemente marginadas "por ser mujeres, por ser indígenas y por tener una discapacidad", terrible realidad. Juventino habla de tener un líder para conseguir mejores condiciones por parte del Estado, para lograr una marcha del orgullo de los discapacitados, como la marcha gay, pero veo en él el líder que tanto aclama. Y en ello veo su capacidad de ser solidario estructural, excelente negociador y gran ideólogo. Maravilloso personaje de nuevo de la sierra norte en meras tierras oaxaqueñas, quien como señala Marco Antonio Cruz el fotógrafo, Juventino habita la oscuridad.

Cierra este libro un texto de la investigadora Martha Romero Mendoza con el caso extremo de una jovencita en situación de calle, consumidora de sustancias, acusada de robo, que requiere de una ayuda y un apoyo externo de manera clara: "La solidaridad en una menor insumisa, infractora y consumidora de sustancias adictivas", y en este apartado de microhistorias, me parece que el cierre es muy atractivo y sólido porque permite ver de nuevo la marginalidad, la condición de calle, la presencia de las mujeres bajo el influjo de enervantes, y finalmente cuáles son los conceptos del grupo de solidaridad adquirida me parece, por ser marginales y por vivir condiciones de vida extrema. Y es con este trabajo que podemos observar desde el Tribunal de Menores Infractoras que estaba en Coyoacán, --en 2008 dejó de estar 
ahí--, una historia desgarradora que suceden en el ámbito de las grandes ciudades, como los últimos tres personajes del libro lo traen a cuenta. Sin su padre, con una madre vuelta a casar con un padrastro abusivo, acosador, violador en potencia, con sus nuevos tíos consumidores de drogas, en un entorno inseguro como lo va mostrando la investigadora Martha Romero, que la orilla a buscar el cobijo en el suelo, en la calle, y es ahí donde puede encontrar una disfuncional, pero efectiva solidaridad. Compartiendo puertas, piso, condiciones denigrantes, pero cobijada para que aprenda un oficio de microbusera, pero finalmente consumidora de diversas sustancias que la llevan a condiciones cada vez más caótica. Su presencia en el tribunal obedece a un robo para ayudar a un amigo. Y ese concepto de solidaridad devuelta, su sacrificio en pro del otro más necesitado es lo que veremos construido con su testimonio, desde la mirada holista que contextualiza y profundiza las características individuales en un entorno de múltiples interacciones, para la comprensión contextual de los eventos, los procesos que ha vivido la informante de la investigadora aunado al concepto de dádiva, que lo analiza desde una perspectiva de la deuda, adquirida o no, en el terreno de la solidaridad y que la autora caracteriza en cinco diferentes formas. Y me parece que será la última la que representa este caso: la encontrada en los lazos primarios..., aquí de los pares, que socialmente han sido los "nones" de la sociedad. Un discurso bien construido que enmarca el caso de Alexis, paso a paso y permite comprender sus motivos, causas y efectos que la llevaron a la condición de calle y los aspectos solidarios que presentan estos grupos marginales, que se ha pensado no existe entre ellos la solidaridad. Es factible observar con este caso cómo claramente se puede generar vínculo desde la perspectiva del "otro", el "ajeno". Son lazos familiares que se gestan en las orillas de la sociedad procurándose ayuda mutua para evitar mayores erosiones sociales, físicas y psicológicas entre ellos. Unidos por la ausencia de familia, por el abuso de la autoridad, por el consumo de sustancias y la insumisión, es decir, por el deseo de no integrarse, el rechazo a integrarse por elección.

Es este cierre importante porque justo deja ver el otro extremo de la sociedad, los grupo marginales y marginados en donde el colectivo estructural no funciona como apoyo, como sustento y nos deja ver cómo se crean los lazos con ajenos, con 
los no propios, en esta profunda necesidad humana de que la solidaridad sea colectiva o individual, pero la presencia del otro como dintel, como contrafuerte en los movimiento sociales, políticos, en las huelgas, en la discapacidad, en las necesidades de género, en las migraciones, ahí es dónde debe abrevar la solidaridad de propios y/o ajenos, como lo hemos visto con este maravilloso y clarificador libro en dos vertientes sustanciales: el concepto de solidaridad, construido con base en la historia oral, una gran herramienta de la historial social, política y cultural, los testimonios colectivos e individuales que permiten acercarnos reconocernos en diversos momentos de nuestra historia.

Cada uno de los casos colectivos o particulares, dejan en claro que somos un país de grandes capacidades y posibilidades ante los profundos malestares sociales. Para muestra nuestro septiembre negro, con los terremotos, ahí vivimos de nuevo esa solidaridad amplia nacional, ciudadana e internacional. Ahí se visibilizó la posibilidad de ayudar, de proveer, de estar presentes. Ahí también la sensación de inutilidad o desesperanza se vio de nuevo entre los escombros. Aquí estamos con el 1968 y el 1971 a cuestas, con los 43 de Ayotzinapa, con las desaparecidas, con las muertas del día a día, esperando soluciones drásticas, claras contundentes. Hoy más que nunca bajo esta pandemia la solidaridad invisible se permea, a lo lejos, con cubrebocas y caretas, con gel y conciencia del contagio, todo ello es fundamental en el día a día, para unos incomprensible, para otros inexistente, pero sin esta solidaridad a la distancia de responsabilidad individual y colectiva, sin ello, este evento se prolongará y cobrará muchas vidas más.

Sean en colectivo o no, la inminente capacidad de ayudar, de estar ahí, de no dejar caer es una señal, me parece y forma parte de la salud mental pública y privada. Algo que es bueno cultivar en familia y en la vida privada, ahora es necesario retomarlo como la posibilidad de una colectividad militante, con conciencia, para ayudar y ser solidario de manera conjunta desde lo individual.

Solo para ponderar quisiera poner en un listado todos los matices de la solidaridad del libro:

Solidaridad política, filosófica, performativa, construida; solidaridad internacional, obrera, revolucionaria, de servicio, de semejanza, feminista, de 
género, conflictiva, solidaridad sin fronteras, solidaridad y proximidad, solidaridad e identidad, actos solidarios por identificación, popular, de conciencia y empatía, solidaridad y caridad, solidaridad intermitente, concreta, solidaridad y consenso. En síntesis, me parece como dicen los autores y lo vemos a lo largo del libro es innegable que la solidaridad es multidimensional.

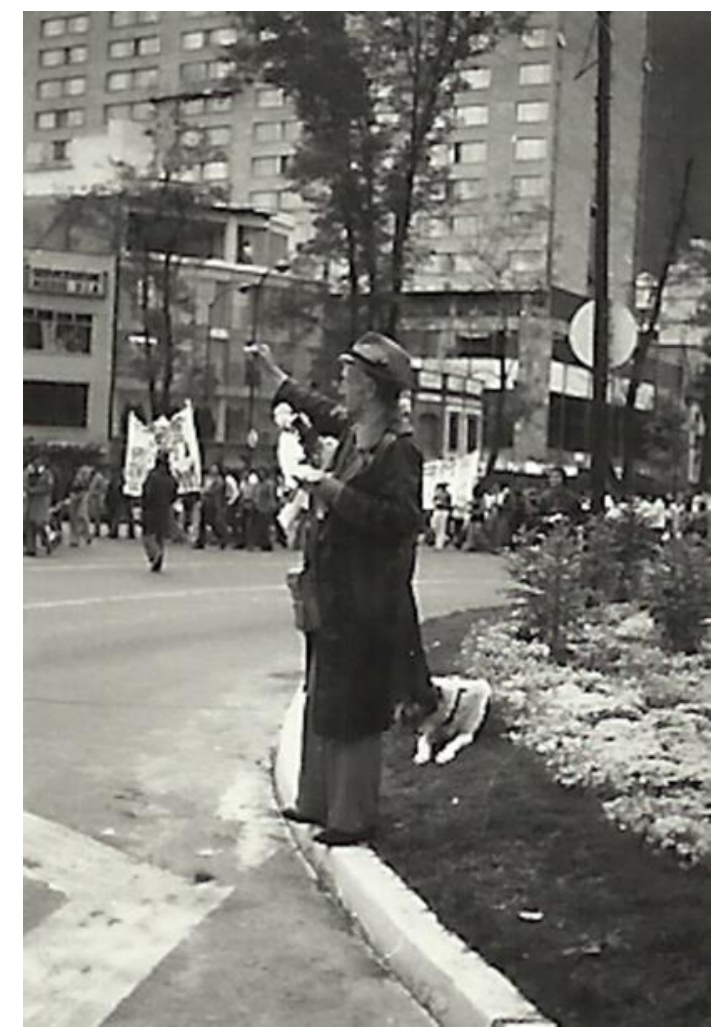

Fotografía: Rebeca Monroy Nasr. Solidaridad urbana con flores, perro y un deseo en la piel. Marcha, junio, 1983. ARMN. 